\title{
Cytoreductive Surgery and Hyperthermic Intraperitoneal Chemotherapy in the Management of Peritoneal Surface Malignancies of Colonic Origin: A Consensus Statement
}

J. Esquivel,${ }^{1}$ R. Sticca, ${ }^{2}$ P. Sugarbaker, ${ }^{3}$ E. Levine,${ }^{4}$ T. D. Yan,${ }^{3}$ R. Alexander, ${ }^{5}$ D. Baratti, ${ }^{6}$ D. Bartlett, ${ }^{7}$ R. Barone,${ }^{8}$ P. Barrios, ${ }^{9}$ S. Bieligk,${ }^{10}$ P. Bretcha-Boix,${ }^{11}$ C. K. Chang, ${ }^{12}$ F. Chu,${ }^{13}$ Q. Chu ${ }^{14}$ S. Daniel,${ }^{13}$ E. deBree, ${ }^{15}$ M. Deraco,${ }^{6}$ L. Dominguez-Parra,${ }^{16}$ D. Elias,${ }^{17}$ R. Flynn,,${ }^{10}$ J. Foster, ${ }^{18}$ A. Garofalo, ${ }^{19}$ F. N. Gilly, ${ }^{20}$ O. Glehen, ${ }^{20}$ A. Gomez-Portilla, ${ }^{21}$ L. GonzalezBayon, ${ }^{22}$ S. Gonzalez-Moreno, ${ }^{23}$ M. Goodman,${ }^{24}$ V. Gushchin, ${ }^{25}$ N. Hanna, J. Hartmann, ${ }^{26}$ L. Harrison, ${ }^{27}$ R. Hoefer, ${ }^{28}$ J. Kane, ${ }^{29}$ D. Kecmanovic, ${ }^{30}$ S. Kelley, ${ }^{31}$ J. Kuhn, ${ }^{32}$ J. LaMont,${ }^{32}$ J. Lange ${ }^{39}$ B. Li ${ }^{14}$ B. Loggie, ${ }^{18}$ H. Mahteme,${ }^{33}$ G. Mann,${ }^{34}$ R. Martin,${ }^{35}$ R. A. Misih, ${ }^{36}$ B. Moran,${ }^{37}$ D. Morris, ${ }^{13}$ L. Onate-Ocana,${ }^{38}$ N. Petrelli, ${ }^{36}$ G. Philippe, ${ }^{39}$ J. Pingpank,${ }^{40}$ A. Pitroff, ${ }^{1}$ P. Piso, ${ }^{41}$ M. Quinones, ${ }^{42}$ L. Riley ${ }^{43}$ L. Rutstein,${ }^{44}$ S. Saha,${ }^{45}$ S. Alrawi,${ }^{29}$ A. Sardi,${ }^{25}$ S. Schneebaum ${ }^{46}$ P. Shen,${ }^{4}$ D. Shibata, ${ }^{31}$ J. Spellman,${ }^{47}$ A. Stojadinovic ${ }^{48}$ J. Stewart, ${ }^{4}$ J. Torres-Melero, ${ }^{49}$ T. Tuttle,${ }^{50}$ V. Verwaal, ${ }^{51}$ J. Villar, ${ }^{52}$ N. Wilkinson, ${ }^{53}$ R. Younan, ${ }^{6}$ H. Zeh, ${ }^{7}$ F. Zoetmulder, ${ }^{51}$ and G. Sebbag ${ }^{54}$

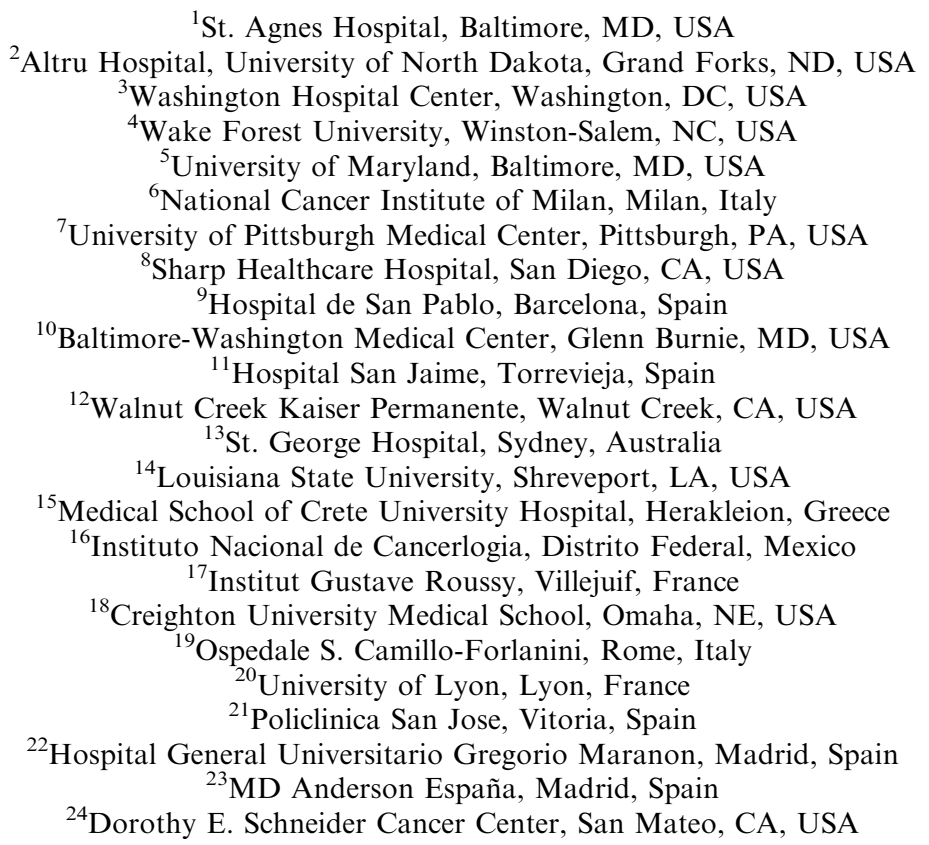

Published online January 8, 2008.

The online version of the original article can be found under doi:10.1245/s10434-006-9185-7

Address correspondence and reprint requests to: J. Esquivel; E-mail: jesusesquivel@yahoo.com 


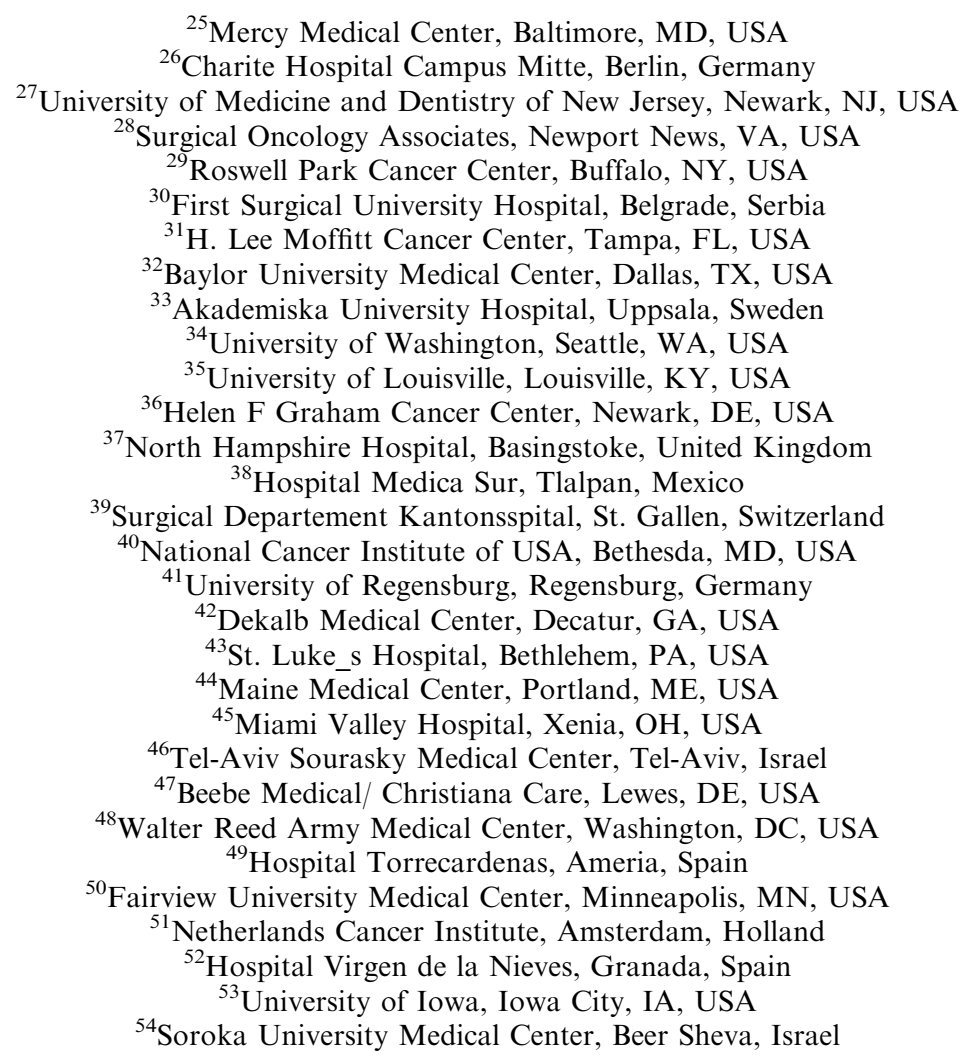

Erratum to: $10.1245 / \mathrm{s} 10434-006-9185-7$

Annals of Surgical Oncology 14:128-133

J. Lange's affiliation appeared incorrectly in the byline of this article and in the HTML file. The correct listing of authors and affiliations appears above: 